\title{
ASSESSING THE SIGNIFICANCE OF METEOROLOGICAL PARAMETERS TO THE MAGNITUDE OF URBAN HEAT ISLAND (UHI)
}

\author{
Babatunde Wasiu ANIBABA \\ Department of Geography, University of Ibadan, Ibadan, Nigeria \\ e-mail: anibaba.babatunde@yahoo.com \\ Olufemi Sunday DUROWOJU * \\ Department of Geography, Osun State University, Osogbo, Osun State, Nigeria \\ e-mail: olufemi.durowoju@uniosun.edu.ng
}

Oluwatola Ibukun ADEDEJI

National Space Research and Development Agency, Nigeria

e-mail: oluwatola2002@yahoo.com

Citation: Anibaba, B.W., Durowoju, O. S., Adedeji, O. I (2019). Assessing the Significance of Meteorological Parameters to the Magnitude of Urban Heat Island (UHI). Analele

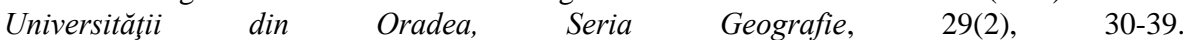
https://doi.org/10.30892/auog.292103-798

\begin{abstract}
An assessment of the relationship of UHI Intensity with wind speed, cloud cover and relative humidity was carried out in the city of Ibadan, Nigeria. Data on wind speed, relative humidity, cloud cover, minimum, maximum and mean temperature were sourced from six weather stations from 1993-2012. To enable proper extraction of climatic parameters and ensure adequate spatial coverage, eighteen-point locations were randomly selected by dividing the study area into 40 grid cells of $1 \mathrm{~km} \times 1 \mathrm{~km}$ across the study area. The result of regression model showed that the independent variables account for only about $52.3 \%$ of the observed variation in UHI intensity, while the F-statistic indicates there was a significant relationship between the dependent and independent variables $\left(\mathrm{F}_{\mathrm{x}}^{2}=8.806, \mathrm{P} \leq 0.05\right)$. It was further revealed that wind speed was found to be a significant predictor of UHI intensity with the latter weakening with increasing wind speed. Further analysis showed that at a critical wind speed of $7 \mathrm{~m} / \mathrm{h}$, UHI becomes unnoticeable. Relative humidity and cloud cover showed a negative and weak relationship with UHI Intensity. The study concluded that urban heat island intensity varies significantly and it is strongly influenced by meteorological parameters particularly wind speed. This study therefore recommends that more weather-monitoring stations and highly sensitive equipment for monitoring the climatic elements at regular intervals should be set up.
\end{abstract}

Key words: Urban Heat Island (UHI), Wind Speed, Meteorological Parameters

$$
\text { * } \quad * \quad * \quad * \quad * \quad *
$$

${ }^{*}$ Corresponding Author 


\section{INTRODUCTION}

The increasing recognition of urbanization and its associated problems modify the climate of cities. These result in the climatic condition of cities being slightly different from that of the surrounding areas. Urban-induced or urban-modified weather and climate represent one of the major effects of the Urban Heat Island (UHI) phenomenon. UHI is best described as the situation where the temperature of large metropolitan cities is notably higher than the surrounding rural areas with the main cause being the modification and replacement of natural land surfaces with urban structures that possess materials which are capable of storing shortwave radiation. A study by Oke (1987) affirmed that it is a feature commonly observed in many cities, and its characteristics have been extensively studied in the past decades mostly in developed countries.

UHI has received a great deal of attention in the literatures. The scientific interest ranges from the noble work on urban effects on precipitation (Lowry, 1998) to the theoretical (Lin and Smith, 1986) and numerical (Baik et al., 2001) studies which focused on UHI effect on convection and precipitation. It is evident in these studies that an increase in the city's temperature compared to the surrounding rural suburb is of advantage in the temperate regions where winter heating bills are significantly reduced, whereas, it constitutes a disadvantage in the tropical areas as it results in climatic discomfort and impairs the well-being of city dwellers. Also, an increase in the total amount of rainfall is likely to be beneficial in period of scarce precipitation, but, otherwise in areas where excessive rainfall disrupts daily activities.

The intensity of UHI has been found to vary according to locations within the city. For example, the city centre, core areas or central business districts (CBD) impact more on the surface temperature than the suburban areas due to the increased heat capacity of the urban structures. On the nature of UHI in different cities of the world, scholars have concluded that even for cities with similar climate differences, the UHI can be explained majorly in terms of its form and location. Nasrallah et al. (1990) found the UHI of Kuwait City to be less intense than that of Phoenix, Arizona. They explain these differences in terms of the form and location of the city on the Arabian Gulf. The magnitude of urban heat island (UHI) has also been widely associated to the local meteorological factors (Kim and Baik, 2001). With regards to ambient climatic conditions, it is a common fact that UHIs strongly relate to cloud cover and wind speed such that at clear and windless night, UHI becomes prominent (Montavez et al., 2000). The intensity of UHI is proven to exhibit diurnal and seasonal cycles and this is modulated by cloud and wind conditions (Ackerman, 1985). The UHI intensity is equally reported to be pronounced during the night-time, tends to be strong in the warm seasons of the year and weak in the cold season in the tropics (Oluwamimo, 2006).

Several studies have examined the impact of some meteorological parameters such as cloud cover and wind speed on UHI intensity (Ackerman, 1985; Eliasson, 1996; Figuerola and Mazzeo, 1998; Magee et al., 1999). It is pertinent to explore this aspect of urban climate as it determines the strength and degree of UHI occurring in a city. This relationship came to limelight in the pioneering paper of Sundborg (1950) who first relate UHI intensity to meteorological elements such as wind speed, cloud cover and relative humidity using a multiple linear regression method. His work showed that wind speed and cloud cover negatively correlated with UHI intensity in Uppsala, Sweden. It is obvious from this revelation that majority of these studies were carried out in more developed parts of the world (Auer, 1981; Ackerman, 1985; Morris et al., 2001; Chow and Roth, 2006; Fortuniak et al., 2006; Yow and Carbone, 2006) but very few studies if any, in subSaharan region of Africa have assessed the role of meteorological parameters in the intensity of UHI. The available ones (Robaa, 2003; Enete et al., 2012) engaged traditional method by examining temperature difference between urban and rural sites but this study clearly departs from the convention in that it combines the traditional approach of monitoring UHI with a satellitebased methodology. Against this backdrop, the study assessed the significance of meteorological parameters to the magnitude of UHI in Ibadan, Nigeria. The choice of Ibadan City was because of its expansion as the largest metropolis in West Africa. 


\section{STUDY AREA}

Ibadan is located within Latitude $7^{\circ} 15^{\prime} \mathrm{N}$ and $7^{\circ} 30^{\prime} \mathrm{N}$ of the Equator and Longitude $3^{\circ} 45^{\prime} \mathrm{E}$ and $4^{\circ} 00^{\prime} \mathrm{E}$ of the Greenwich Meridian. Ibadan is located near the forest-grassland boundary of south-western Nigeria. Ibadan metropolis currently hosts the administrative capital of Oyo state. Generally, five local government areas (LGAs) make up Ibadan metropolis out of eleven that makes Ibadan region and these are Ibadan North, Ibadan Northwest, Ibadan Northeast, Ibadan Southeast, and Ibadan Southwest while the six Peri-urban LGAs are Egbeda, Akinyele, Ido, OnaAra, Oluyole, Lagelu. In view of its location, the climate of the study area is that of a tropical wet and dry climate. Largely, it is strongly influenced by the West African monsoon climate, marked by a distinct seasonal shift in the wind pattern, radiation and cloud cover due to its latitudinal location. The two most defined rainfall seasons are the dry and wet season. The period of wet season is usually between March and October when the area is under the influence of the prevailing moist, maritime south-west monsoon winds which blow inland from the Atlantic Ocean while the dry season occurs normally from November to February when the dry, dust-laden northeast trade winds blow from the Sahara Desert. The mean annual rainfall of Ibadan is about $1205 \mathrm{~mm}$, falling in approximately 109 days. The temperature of Ibadan is characterized by constant high temperatures throughout the year with mean monthly temperature fluctuating around $26.6^{\circ} \mathrm{C}$, while the mean monthly minimum and maximum temperature is rarely below $21.4^{\circ} \mathrm{C}$. Highest temperatures usually occur around February and March which coincides with the period that mark the end of the dry season. Relative humidity is constantly high throughout the year with annual average greater than 80 percent, and the period of highest relative humidity coincide with the rainy season. The cloud cover is high with about 80 percent in the rainy season (Adebayo, 1985).

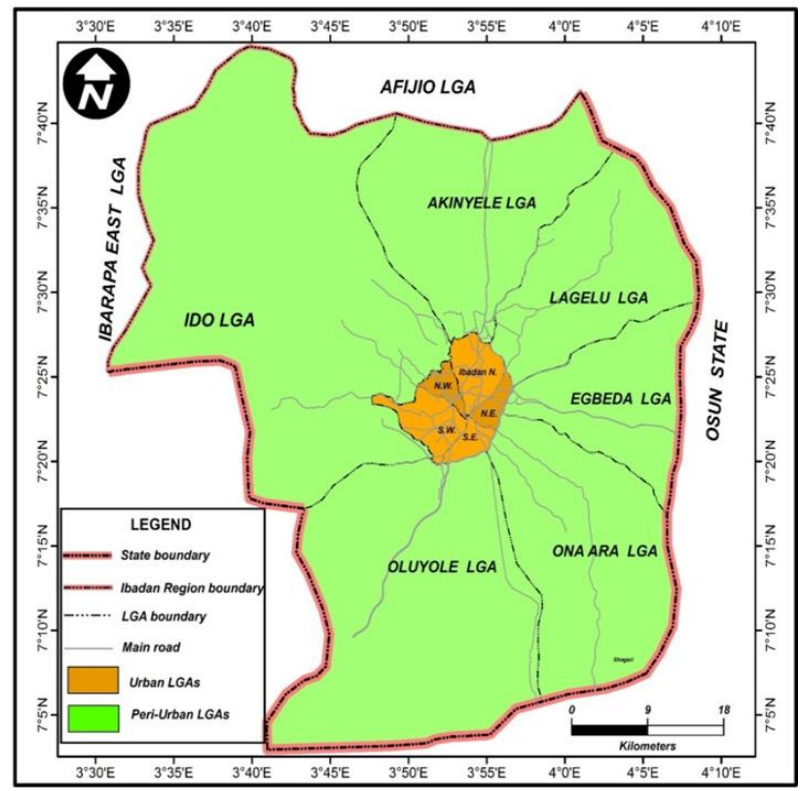

Figure 1. Map Showing the Study Area (Ibadan Metropolis and its Peri-Urban Areas) Source: Digitized from Google Earth Pro. (2015)

The city is the largest in Tropical Africa and the largest indigenous metropolitan area in sub-Saharan Africa (Adedimeji et al., 2008). Ibadan's population grew from an estimated figure of 170,000 in 1911 to 459,196 in 1952 . By 1963 , its population had reached 625,000 . The 1991 census put the population of the city at about 1.45 million people. Together, the region of Ibadan has a population of over $2,550,593$ persons according to the 2006 population census. The Ibadan 
metropolis local government areas account for 1,338,659 persons, while the six other local government areas that constitute the rest of the region account for slightly less than one-third of the population for the state (National Population Commission, 2006). The total area of developed land in Ibadan increased from 100 ha in 1830 to $12 \mathrm{~km}^{2}$ in 1931 . But by the mid-twentieth century, the contiguously built-up area of Ibadan grew from $30 \mathrm{~km}^{2}$ in 1963 to $214 \mathrm{~km}^{2}$ in 1988 (Oluseyi, 2006). By the year 2000, it expanded covering an area of about $400 \mathrm{~km}^{2}$. The expansion of the urban area in terms of its growth during the latter half of the $20^{\text {th }}$ century (from $40 \mathrm{~km}^{2}$ to $250 \mathrm{~km}^{2}$ in the 1950s and 1990s respectively) reveals that there has been an underestimation of the total growth of the region, and its locational advantage made it a favorable city for educational, sociopolitical, commercial and industrial activities.

\section{MATERIALS AND METHODS}

As shown in table 1 and figure 2 weather data were obtained from both the conventional and point locations (satellite extract). The ground-based weather station consists of the agricultural and meteorological stations which are the Geospatial Unit of the International Institute of Tropical Agriculture (IITA), Cocoa Research Institute of Nigeria (CRIN), Institute of Agricultural Research and Training weather unit (IARandT), Forestry Research Institute of Nigeria (FRIN) and Ibadan Airport (through: Nigeria Meteorological Station (NIMET).

Table 1. The Name of Weather Stations and their Geographical Attributes

Source: Authors field Survey, 2015

\begin{tabular}{|l|l|l|l|l|l|}
\hline S/N & Station Name & Type & Latitude & Longitude & Elevation (m) \\
\hline 1 & NIMET & Synoptic Station & $7^{0} 26^{\prime} 45.0^{\prime \prime}$ & $3^{0} 53^{\prime} 26.0^{\prime \prime}$ & $197 \mathrm{~m}$ \\
\hline 2 & CRIN & Agro-climatological Station & $7^{0} 14^{\prime} 58.0^{\prime \prime}$ & $3^{0} 50^{\prime} 56.2^{\prime \prime}$ & $130 \mathrm{~m}$ \\
\hline 3 & IAR and T & Agro-climatological Station & $7^{0} 22^{\prime} 46.2^{\prime \prime}$ & $3^{0} 50^{\prime} 37.7^{\prime \prime}$ & $146 \mathrm{~m}$ \\
\hline 4 & IITA & Agro-climatological Station & $7^{0} 29^{\prime} 48.0^{\prime \prime}$ & $3^{0} 54^{\prime} 12.4^{\prime \prime}$ & $211 \mathrm{~m}$ \\
\hline 5 & FRIN & Agro-climatological Station & $7^{0} 23^{\prime} 30.9^{\prime \prime}$ & $3^{0} 51^{\prime} 47.7^{\prime \prime}$ & $187 \mathrm{~m}$ \\
\hline 6 & NIHORT & Agro-climatological Station & $7^{0} 24^{\prime} 21.6^{\prime \prime}$ & $3^{0} 51^{\prime} 03.0^{\prime \prime}$ & $200 \mathrm{~m}$ \\
\hline
\end{tabular}

"Index of UHI Intensity" is a technique most commonly used to detect the influence of urbanization on the climate of urban centres which considers the difference in temperature between a representative of urban and rural station (Yague et al., 1991; Jauregui et al., 1992; Karaca et al., 1995). This study therefore chooses Cocoa Research Institute of Nigeria (CRIN) as rural reference station and the difference in temperature between the rural site and urban stations (average temperature) were used as a surrogate measure of the urban heat island intensity in Ibadan. The choice of the reference station is based on the fact that only the green areas in the city were observed to have the lowest temperatures. The only station that closely approximates this feature is the weather station in Idi-Ayunre. The station was therefore considered as a baseline to assess UHIs at other stations. Data on wind speed, relative humidity, cloud cover, minimum, maximum and mean temperature were obtained from the stations for a period of twenty years (1993-2012).

In addition to the climatic data sourced from the ground weather stations, satellite data were also obtained to ensure adequate spatial coverage of the study area. In achieving this, the dataset was first of all downscaled to the study area. The entire area was divided into 40 grid cells (or pixels) of $1 \mathrm{~km} \times 1 \mathrm{~km}$. Using the 'Fish-net' technique in the ArcGISTM software, point locations were randomly selected and the weather data for each point were extracted so as to get a good representation of the terrains therein. Going by the conclusions by Mohan et al., (2012) who used $32 \mathrm{~km} \times 32 \mathrm{~km}$ grids in their analysis, these are expected to provide accurate measurements of UHI intensity and provide a basis for comparison with in situ measurements which can be used to detect major hotspots and for assessing hotspots for other sites and times when in situ measurements are inadequately available. Overall, twenty-four (24) sites were chosen throughout the city which include the six conventional ground station (WS) and eighteen points of satellite data extract. Figure 2 shows the location of the sampled sites on the map of Ibadan. The data 
extracted are entered into relevant software such as Microsoft Excel Professional Plus 2013, Statistical Package for the Social Sciences (SPSS) and other statistical tools.

Statistically, multiple regression analysis was used to assess the effects of each meteorological parameter on the intensity of UHI in Ibadan. The UHI intensity (which is the dependent variable) was regressed on the three meteorological elements (predictors). It is aimed at establishing the level of relationship as well as the contribution of each meteorological parameter to the observed heat island intensity.

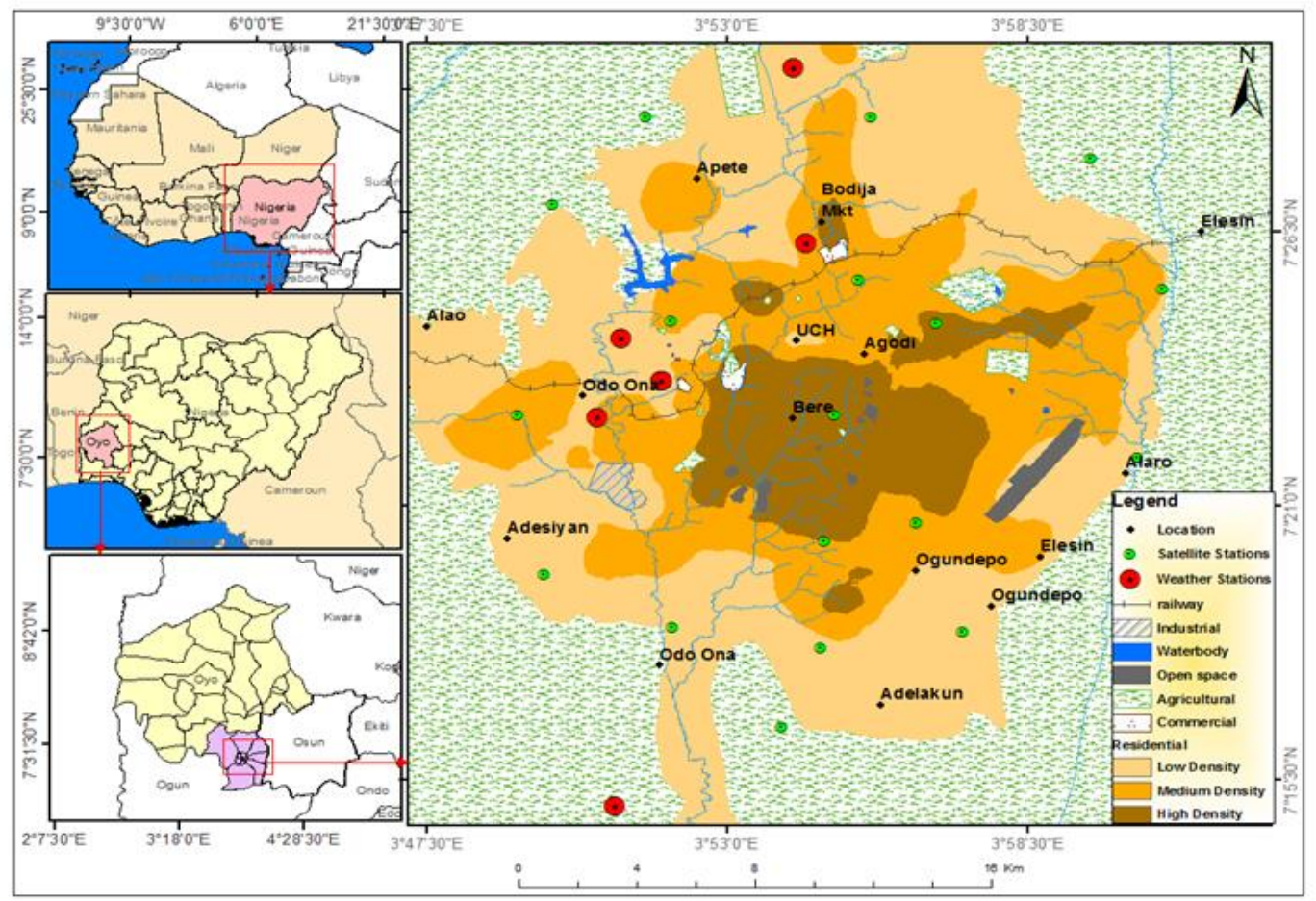

Figure 2. Locations of Satellite Data Extract and Weather Stations across the Study Area Source: Digitized from Google Earth Pro. (2015)

\section{RESULTS AND DISCUSSION}

Urban heat island intensity is closely related to the prevailing meteorological conditions. Numerous studies have shown the impact of meteorological parameters such as cloud cover and wind speed on the intensity of UHI (Ackerman, 1985; Eliasson, 1996; Figuerola and Mazzeo, 1998; Magee et al., 1999; Mohan et al., 2012). Here, UHI intensities were compared with relevant meteorological parameters to determine if similar relationship exists.

\section{Significance of Wind Speed on Urban Heat Island Intensity}

Wind speed is an important parameter in urban areas influencing the health, outdoor/indoor comfort, air quality and energy consumption. In relation to ambient climatic conditions, wind speed largely impacts the magnitude of UHI. High winds influence the cooling difference between the urban and Peri-urban areas and thus, reduces the UHI effect. Conversely, calm conditions with clear skies create room for large UHI effect.

In figure 3, UHI is related to the wind speed (table 4). As the wind speed increases, the UHI intensity presents a tendency to decrease as there is an inverse relationship between wind speed and UHI intensity. The $\mathrm{R}^{2}$ value shows that wind speed only explains about $33.5 \%$ variation in UHI intensity while about $66.5 \%$ is left unaccounted for. It would be observed that the maximum UHI 
intensity actually began to decline for wind speeds greater than $3 \mathrm{~m} / \mathrm{h}$. However, just like other cities, higher magnitudes of UHI intensity in Ibadan were observed to occur during situations of atmospheric calm. In fact, the highest magnitude of UHI intensity occurred with winds of 2 to $4 \mathrm{~m} / \mathrm{h}(66.7 \%)$.

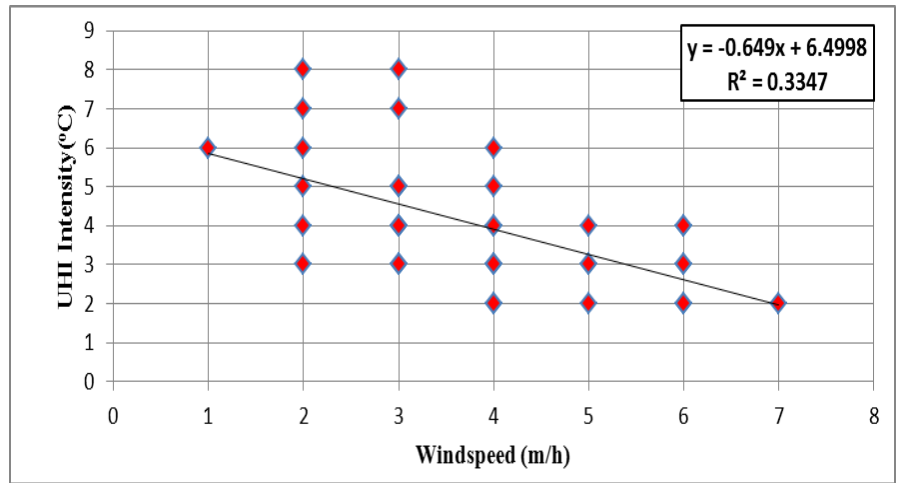

Figure 3. Relationship between Mean Wind Speed and UHI Intensity Source: Authors field Survey, 2015

In addition, the strong UHI intensity $\left(>4^{\circ} \mathrm{C}\right)$ occur, more frequently, with winds between 2 to $4 \mathrm{~m} / \mathrm{h}(54.2 \%)$ and 4 to $6 \mathrm{~m} / \mathrm{h}(21 \%)$ whilst, the thermal contrasts between the two sites seem to disappear for very strong winds $\left(>7^{\circ} \mathrm{C}\right)$. This condition suggests that there can be a critical wind speed beyond which the UHI phenomenon becomes unnoticeable. If the threshold of $2^{\circ} \mathrm{C}$ is considered as a case indicative of the absence of UHI, the critical wind speed is approximately 7 $\mathrm{m} / \mathrm{h}$. This therefore supports the claim that very strong winds prevent the development of the UHI. Winds of about 6 and $7 \mathrm{~m} / \mathrm{s}(13.3$ and $15.5 \mathrm{~m} / \mathrm{h})$ are critical values for the existence of the maximum UHI intensity in Seoul, South Korea and Salamanca, Spain (Kim and Baik, 2001; Alonso et al., 2003). It was also discovered that UHI occurred with winds in every direction. However, strong UHI intensity occurs more frequently with south western and south-south western winds.

\section{Significance of Relative Humidity on Urban Heat Island Intensity}

Humidity is a term that describes the amount of water vapour in the air. It is one of the important factors that influence the energy budget and human physiologic comfort (Adebayo, 1985). The result from figure 4 showed that, similar to wind speed, relative humidity negatively correlates with UHI intensity, although the relationship is very weak $\left(\mathrm{R}^{2}=12 \%\right)$ meaning that the UHI intensity is weakened as relative humidity increases.

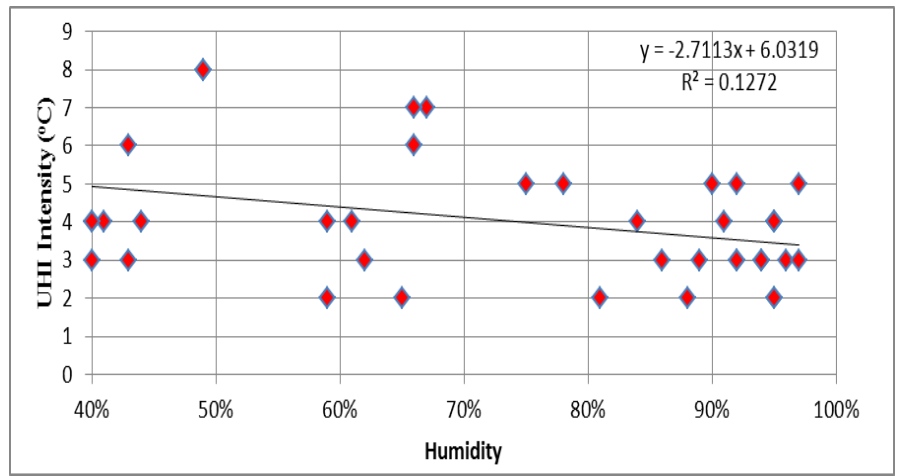

Figure 4. Relationship between Humidity and UHI Intensity Source: Authors field Survey, 2015 
It is also obvious in the scatter plot in figure 4 that much larger magnitudes of UHI intensity in Ibadan was observed to occur during conditions of high relative humidity, i.e. $72 \%$ of the total data exists in the $60-100 \%$ relative humidity range. This also explains why the heat island intensity of between $4.5-5.0^{\circ} \mathrm{C}$ were reported at the midnight and early morning of the observation period when the atmosphere is more humid and cooler. The highest magnitude of UHI intensity $\left(8.0^{\circ} \mathrm{C}\right)$ occurred during conditions of dryness or hot afternoons when the air is less humid (40-50\%). This condition could be due to the fact that when evaporation from the urban surface takes place, the surface air temperature decreases because of evaporative cooling, and the amount of vapour in the air (relative humidity) increases because of an increase in the water vapour pressure. This, perhaps, explains the reason why UHI intensity tends to decrease as the relative humidity increases in Ibadan.

Table 2. Relationship between UHI and Mean Daily Wind Speed, Relative Humidity and Cloud Cover (Based on 40-Day Sample between October-December, 2014)

Source: Authors field Survey, 2015

\begin{tabular}{|c|c|c|c|c|}
\hline $\mathbf{S} / \mathbf{N}$ & UHI $\left({ }^{\circ} \mathrm{C}\right)$ & Cloud Cover (oktas) & Wind speed $(\mathrm{m} / \mathrm{h})$ & Humidity (\%) \\
\hline 1 & 3 & 0.39 & 3 & 94 \\
\hline 2 & 3 & 0.36 & 2 & 96 \\
\hline 3 & 5 & 0.36 & 2 & 97 \\
\hline 4 & 7 & 0.11 & 3 & 67 \\
\hline 5 & 6 & 0.06 & 4 & 43 \\
\hline 6 & 4 & 0.22 & 3 & 40 \\
\hline 7 & 3 & 0.12 & 6 & 62 \\
\hline 8 & 4 & 0.05 & 5 & 84 \\
\hline 9 & 2 & 0.55 & 4 & 95 \\
\hline 10 & 4 & 0.68 & 4 & 95 \\
\hline 11 & 5 & 0.67 & 4 & 92 \\
\hline 12 & 5 & 0.63 & 3 & 75 \\
\hline 13 & 8 & 0.15 & 3 & 49 \\
\hline 14 & 3 & 0.21 & 3 & 40 \\
\hline 15 & 4 & 0.1 & 6 & 61 \\
\hline 16 & 3 & 0.32 & 5 & 89 \\
\hline 17 & 4 & 0.73 & 4 & 95 \\
\hline 18 & 3 & 0.7 & 3 & 92 \\
\hline 19 & 5 & 0.62 & 3 & 90 \\
\hline 20 & 5 & 0.76 & 3 & 78 \\
\hline 21 & 8 & 0.17 & 2 & 49 \\
\hline 22 & 4 & 0.21 & 2 & 41 \\
\hline 23 & 4 & 0.12 & 6 & 59 \\
\hline 24 & 2 & 0.29 & 6 & 88 \\
\hline 25 & 3 & 1 & 4 & 97 \\
\hline 26 & 3 & 0.76 & 4 & 92 \\
\hline 27 & 4 & 0.75 & 3 & 91 \\
\hline 28 & 6 & 0.57 & 2 & 66 \\
\hline 29 & 4 & 0.1 & 3 & 44 \\
\hline 30 & 3 & 0.28 & 5 & 43 \\
\hline 31 & 2 & 0.16 & 7 & 65 \\
\hline 32 & 3 & 0.11 & 6 & 86 \\
\hline 33 & 3 & 0.16 & 4 & 94 \\
\hline 34 & 2 & 0.13 & 4 & 95 \\
\hline 35 & 4 & 0.11 & 3 & 95 \\
\hline 36 & 7 & 0.02 & 2 & 66 \\
\hline 37 & 6 & 0.14 & 1 & 39 \\
\hline 38 & 4 & 0.26 & 3 & 40 \\
\hline 39 & 2 & 0.17 & 6 & 59 \\
\hline 40 & 2 & 0.12 & 5 & 81 \\
\hline
\end{tabular}




\section{Relationship of Urban Heat Island with Wind Speed, Relative Humidity and Cloud Cover}

Table 4 presents the relationship between Urban Heat Island Intensity (UHII) and wind speed, relative humidity and cloud cover.

Table 3. Result of Multiple Regression Statistics

Source: Authors field Survey, 2015

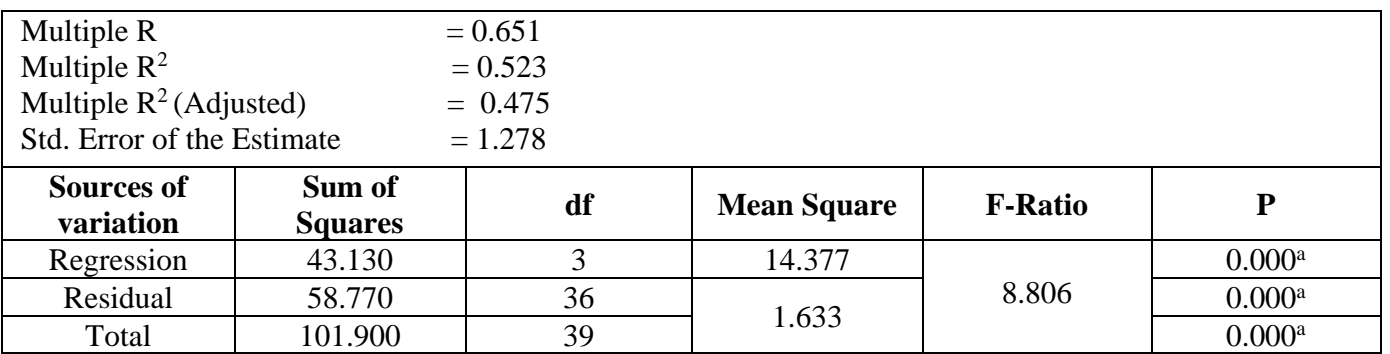

a. Predictors: (Constant), Cloud, Wind, Humidity

b. Dependent Variable: UHI

Table 4. Result of Multiple Regression Statistics

Source: Authors field Survey, 2015

\begin{tabular}{|c|c|c|c|c|c|}
\hline & \multicolumn{2}{|c|}{ Unstandardized Coefficients } & $\begin{array}{c}\text { Standardized } \\
\text { Coefficients }\end{array}$ & Sig. \\
\cline { 1 - 3 } 1 Model & B & Std. Error & Beta & & \\
\hline (Constant) & 7.993 & .863 & & 9.259 & .000 \\
\hline Wind & -.631 & .149 & -.562 & -4.226 & .000 \\
\hline Humidity & -.019 & .012 & -.255 & -1.664 & .105 \\
\hline
\end{tabular}

a. Dependent Variable: UHI

The regression equation obtained from the analysis presented in table 4 is given as;

$$
\mathrm{Y}=7.993-0.631 \mathrm{X}_{1}-0.19 \mathrm{X}_{2}-0.004 \mathrm{X}_{3}
$$

Where, $\mathrm{Y}=$ Urban Heat Island Intensity

$\mathrm{X}_{1}=$ Wind speed

$\mathrm{X}_{2}=$ Humidity

$\mathrm{X}_{3}=$ Cloud cover

The regression model obtained from the analysis as presented in table 4 shows that the three independent variables (wind speed, relative humidity and cloud cover) account for $52.3 \%$ of the explanation of urban heat island intensity (i.e. the model summary shows that $\mathrm{R}_{2}=0.523$ ). This suggests that other relevant predictors, including those related to synoptic weather, anthropogenic heat and atmospheric pollutants need to be included to increase the variance explained. The Fstatistic from the ANOVA (8.806) has a high significance value indicating that the model significantly explains changes in the dependent variable (UHI Intensity). This implies that UHI Intensity is related to wind speed, relative humidity and cloud cover. However, the interpretation of the individual ' $b$ ' values shows that only wind speed is a significant predictor of UHI Intensity while relative humidity and cloud cover were not. From equation 1 , it can be seen that a unit change in wind speed leads to a change of almost eight times over in the value of UHI Intensity. Wind speed was also found to have a much higher influence on UHI Intensity as indicated by the highest beta weights associated with the parameter (0.631). Relative humidity is the second highest predictor (0.019) while cloud cover is the least of the three important predictors $(0.004)$.

\section{CONCLUSION}

A key component of the study was an assessment of the contribution of meteorological parameters to the magnitude of urban heat island over the study location. UHI Intensity was 
regressed against wind speed, relative humidity and cloud cover to establish the contribution of the meteorological variables to UHI and a regression model was obtained to show this contribution. Of the three meteorological variables, only wind speed and relative humidity were found to be statistically significant while cloud cover was observed not to be significant. The relationship between wind speed and UHI was found to be a strong, inverse one and this confirms what obtains in theory that as wind speed increases, UHI intensity tends to be weakened. The R-squared value of the regression analysis between meteorological variables and UHI Intensity established that only about $52.3 \%$ of the observed variation in UHI Intensity is explained by the meteorological variables used in the study. It was therefore concluded that other factors such as the prevailing synoptic weather, anthropogenic heat and atmospheric pollutants etc. (which account for about $48 \%$ ) could significantly influence the magnitude and characteristics of the UHI as reported in the literature. This study therefore recommended that more weather-monitoring stations and highly sensitive equipment for monitoring the climatic elements at regular intervals should be set up.

\section{REFERENCES}

Ackerman, B. (1985). Temporal march of the Chicago heat island. Journal of Climate and Applied Meteorology, 24(6), 547-554.

Adebayo, Y. R. (1985). The microclimate characteristics within the urban canopy of Ibadan, Doctoral Dissertation, Dept. of Geog., University of Ibadan, Ibadan, Nigeria.

Adedimeji, A. A., Heard, N. J., Odutolu, O., Omololu, F. O., \& Adedimeji, A. A. (2008). Social factors, social support and condom use behavior among young urban slum inhabitants in southwest Nigeria. East African Journal of Public Health, 5(3), 215-22.

Alonso, M. S., Labajo, J. L., \& Fidalgo, M. R. (2003). Characteristics of the urban heat island in the city of Salamanca, Spain. Atmósfera, 16(3), 137-148.

Auer, A. H. (1981). Urban boundary layer. In METROMEX: a Review and Summary (pp. 41-62). American Meteorological Society, Boston, MA 18: 41-62.

Baik, J. J., Kim, Y. H., \& Chun, H. Y. (2001). Dry and moist convection forced by an urban heat island. Journal of applied meteorology, 40(8), 1462-1475.

Chow, W. T., \& Roth, M. (2006). Temporal dynamics of the urban heat island of Singapore. International Journal of climatology, 26(15), 2243-2260.

Eliasson, I. (1996). Urban nocturnal temperatures, street geometry and land use. Atmospheric Environment, 30(3), $379-392$.

Enete, I. C., Officha, M., \& Ogbonna, C. E. (2012). Urban heat island magnitude and discomfort in Enugu urban area, Nigeria. Journal of Environment and Earth Science, 2(7), 77-83.

Figuerola, P. I., \& Mazzeo, N. A. (1998). Urban-rural temperature differences in Buenos Aires. International Journal of Climatology, 18(15), 1709-1723.

Fortuniak, K., Kłysik, K., \& Wibig, J. (2006). Urban-rural contrasts of meteorological parameters in Łódź. Theoretical and applied climatology, 84(1-3), 91-101.

Jauregui, E., Godinez, L., \& Cruz, F. (1992). Aspects of heat-island development in Guadalajara, Mexico. Atmospheric Environment. Part B. Urban Atmosphere, 26(3), 391-396.

Karaca, M., Tayanç, M., \& Toros, H. (1995). Effects of urbanization on climate of Istanbul and Ankara. Atmospheric Environment, 29(23), 3411-3421.

Kim, Y. H., \& Baik, J. J. (2002). Maximum urban heat island intensity in Seoul. Journal of applied meteorology, 41(6), 651-659.

Lin, Y. L., \& Smith, R. B. (1986). Transient dynamics of airflow near a local heat source. Journal of the atmospheric sciences, 43(1), 40-49.

Lowry, W. P. (1998). Urban effects on precipitation amount. Progress in Physical Geography, 22(4), 477-520.

Magee, N., Curtis, J., \& Wendler, G. (1999). The urban heat island effect at Fairbanks, Alaska. Theoretical and applied climatology, 64(1-2), 39-47.

Mohan, M., Kikegawa, Y., Gurjar, B. R., Bhati, S., Kandya, A., \& Ogawa, K. (2012). Urban heat island assessment for a tropical urban airshed in India. Atmospheric and Climate Sciences, 2(2), 127-138.

Montávez, J. P., Rodríguez, A., \& Jiménez, J. I. (2000). A study of the urban heat island of Granada. International journal of climatology, 20(8), 899-911.

Morris, C. J. G., Simmonds, I., \& Plummer, N. (2001). Quantification of the influences of wind and cloud on the nocturnal urban heat island of a large city. Journal of Applied Meteorology, 40(2), 169-182.

Nasrallah, H. A., Brazel, A. J., \& Balling Jr, R. C. (1990). Analysis of the Kuwait City urban heat is land. International Journal of Climatology, 10(4), 401-405.

National Population Commission (2006). Details of the breakdown of the National and State Provisional Population Totals. Official Gazette, 96 (2), 1-42, Federal Republic of Nigeria, Abuja.

Oke, T. R. (1987). Boundary layer climates, $2^{\text {nd }}$ (ed.) Routledge, pp. 435. 
Oluseyi, O. F. (2006). Urban land use change analysis of a traditional city from remote sensing data: The case of Ibadan metropolitan area, Nigeria. Humanity \& Social Sciences Journal, 1(1), $42-64$.

Oluwamimo, S. (2006). The Temporal Structure of the Urban Heat Island in Lagos State, Nigeria. European Geosciences Union. In Geophysical Research Abstracts (Vol. 8).

Robaa, S. M. (2003). Urban-suburban/rural differences over Greater Cairo, Egypt. Atmósfera, 16(3), 157-171.

Sundborg, A. (1950). Local climatological studies of the temperature conditions in an urban area. Tellus, 2(3), 222-232.

Yague, C., Zurita, E., \& Martinez, A. (1991). Statistical analysis of the Madrid urban heat island. Atmospheric Environment. Part B. Urban Atmosphere, 25(3), 327-332.

Yow, D. M., \& Carbone, G. J. (2006). The urban heat island and local temperature variations in Orlando, Florida. Southeastern geographer, 46(2), 297-322.

Submitted:

September 20, 2018
Revised:

April 13, 2019
Accepted and published online

July 11, 2019 